\title{
Revista Piel de Leopardo: a la caza de la Nueva Narrativa y de los jaguares de la transición
}

\author{
Macarena Paz Silva Contreras*
}

\section{Resumen}

Este artículo analiza las críticas expuestas en la revista Piel de Leopardo con respecto al manifiesto de Jaime Collyer redactado en representación de los escritores de la Nueva Narrativa. El discurso de este último está marcado por una imaginería bélico-mercantil, la cual, si bien puede no ser transparente para quien se vale de ella, no por eso deja de ser bastante decidora de la profundidad ideológica forzosamente implantada en la población chilena durante casi veinte años de dictadura militar y su concomitante imposición del paradigma neoliberal. Piel de Leopardo recurre a diversas estrategias para hacer frente a la aceptación de algunos participantes de su nuevo rol en el mercado literario: productores, intermediarios, consumidores, etc. El análisis desglosará el manifiesto de Collyer, focalizándose en las relaciones entre sus supuestos y el entorno social, político y económico del período postdictatorial tal como aparecen en las editoriales de Piel de Leopardo. Para ello se usarán conceptos provenientes de la sociología de la cultura y la teoría de Pierre Bourdieu, en especial el concepto de "campo cultural" y "arte autónomo y heterónomo".

Palabras clave: Nueva Narrativa, revista Piel de Leopardo, postdictadura chilena, sociología de la cultura, campo cultural, autonomía, heteronomía.

\section{Piel de Leopardo magazine: in pursuit of the Nueva Narrativa and transition jaguars}

\begin{abstract}
This article analyzes the criticism displayed in the magazine Piel de Leopardo against Jaime Collyer's manifesto, written on behalf of the writers of the Nueva Narrativa. His discourse is marked by a warlike-mercantile imagery, which although it might not be transparent to those who make use of it, it is nonetheless quite significant of the ideological depth established on the Chilean people during almost twenty years of military dictatorship, along with the imposition of the neoliberal paradigm. Piel de Leopardo resorts to various strategies to face the literary participants' willingness to accept their new role in the literary market: producers, middle-men, consumers, etc. The analysis will divide Collyer's manifesto, shedding light on the relations between its assumptions and the social, political, and economic context of the postdictatorial period as they appear in the magazine's editorial reviews. To accomplish this aim, concepts from the sociology of culture and Pierre Bourdieu's theory will be used, particularly, the concept of "cultural field" and "autonomous and heteronomous art".
\end{abstract}

Key words: Nueva Narrativa. Piel de Leopardo magazine, Chilean postdictatorship, sociology of culture, cultural field, autonomy, heteronomy.

* Doctora @ en Literatura por la Pontificia Universidad Católica de Chile.mpsilvac@uc.cl 


\section{Introducción}

En agosto de 1992 aparece, en medio de la selva chilena, una interesante apuesta en el campo de las revistas culturales extraacadémicas. Se trata de Piel de Leopardo, revista de literatura, crítica y arte que, fundada y dirigida por Jesús Sepúlveda, sólo alcanzó a circular con cinco números. Es cierto, aunque editada con cierta regularidad, esta revista no logró consolidarse como un proyecto de largo aliento y, a menos de tres años de su publicación, debió cerrar sus puertas ${ }^{1}$. No obstante, su importancia radica en el papel que jugó durante el primer quinquenio de la transición en el marco de las apuestas artístico-literarias disensuales al fenómeno editorial de los noventa, llamado Nueva Narrativa, y que corresponde a un grupo de narradores reunidos por la editorial Planeta a partir del año 1987. Al mismo tiempo, esta revista intenta seguir una postura cercana a lo que Pierre Bourdieu denomina arte autónomo, arte que trata de deslindarse del modelo mercantil seguido por los escritores de la Nueva Narrativa y explicitado a través del manifiesto generacional publicado por Jaime Collyer en la revista APSI. Una de las características de Piel de Leopardo es que desmiente los discursos exitistas que han permeado desde el campo económico hacia el campo literario y que a través de sus páginas intenta abrir caminos para entender la cultura de un modo en que lo social es observado desde la productibilidad política de los textos.

\section{De leopardos y jaguares}

La revista Piel de Leopardo ${ }^{2}$ aparece en el ámbito cultural chileno para

1 El mismo año de su cierre Jesús Sepúlveda parte a los Estados Unidos, país en el que hasta la fecha reside. Actualmente se desempeña como académico en el Departamento de Lenguas Romances de la Universidad de Oregón.

2 Hasta el año 2008 la revista continuó en formato electrónico. Sin embargo, distó bastante de lo que inicialmente fue en formato papel. Luego de la partida de Jesús Sepúlveda a Estados Unidos, el escritor Jorge Lagos Nilsson publicó en Buenos Aires una revista del mismo nombre que continuaba lo hecho por la inicial Piel de Leopardo. No obstante, ya no se trataba de la misma revista y el proyecto no pasó del número uno. Esta otra publicación, estaba ideada ya fuera del espacio nacional. En el año 2000, será nuevamente Lagos Nilsson quien intente resucitarla, esta vez con éxito y en la web, aunque distando bastante de la revista que le dio origen. La revista, que puede verse en www.pieldeleopardo.com, se inserta en el contexto latinoamericano de la globalización y tiene una orientación sociológica más que literaria. Como se menciona en su sitio, la revista se abrió con el propósito de: "Servir de puente para la difusión del pensamiento y opinión independientes que se generan en América Latina e informar de lo que ocurre en la base de nuestras sociedades: movimientos sociales, naciones originarias, grupos culturales, asociaciones ciudadanas, preocupación ambiental, etc." (Lagos Nilsson, web). El 2008 la revista cierra sus puertas y pasa a llamarse Sur y Sur, también una publicación periodística independiente, pero ya no con una mirada artístico cultural, sino abiertamente política. De hecho, las nuevas secciones de la revista se denominan: Política, 
dialogar con diferentes concepciones literarias a través de su título. Su intromisión en el espacio público desde una escritura letrada, que dialoga con la teoría literaria y la crítica cultural, responde a un proyecto acotado que se autosustentó durante tres años y que pretendió cuestionar el discurso exitista, tanto económico como literario, con que se había iniciado la transición a la democracia, para dar, además, una visión propia sobre el rol de poeta y del intelectual como agente de la memoria. Por otra parte, la revista se transformó en un referente literario que creó desde la crítica y la creación sus propios circuitos, llegando incluso a distribuirse en Argentina a través del poeta Jorge Lagos Nilsson 3 . No se trataba sólo de "un medio impreso sino que también [de] un colectivo de escritores y artistas involucrados en la praxis cultural inmediata" (Sepúlveda, Piel de Leopardo: 14...), que participó en diversas ferias del libro chilenas y que además organizó recitales poéticos y charlas literarias en Santiago, La Serena, Concepción, Puerto Montt y Puerto Varas. La intervención en el espacio real por medio del colectivo, no sólo de poetas sino también de fotógrafos y músicos (entre ellos Álvaro Hope, Paco Toledo, Marta Román, Claudio Bertoni y Joe Vasconcellos) se puede leer como estrategia para apelar a la contingencia desde la creación de un producto cultural orientado a circuitos de intereses híbridos en que se incluye a escritores que no figuraban en los medios populares o de gran circulación y recepción mediática, como por ejemplo Pablo y Winett de Rokha, Clarice Lispector, Mahfrud Massis, T.S.Eliot, Tomas Harris y Miguel Vicuña Navarro, entre otros.

Para entender el lugar en el cual Piel de Leopardo se ubica con respecto al debate en torno a la literatura chilena de los noventa y en qué lugar del campo cultural ${ }^{4}$ se posiciona con respecto a otras estéticas literarias,

Economía, Cultura, Ambiente, Sociedad, Opinión, Humor, Participación Ciudadana y Ciencia y Tecnología. Estas secciones estaban en la antigua Piel de Leopardo, pero subordinadas a la sección 'Noticias' y no como el esqueleto central de la revista, como ocurre con Sur y Sur (véase www.surysur.net).

3 También llegó a regiones: Valparaíso, Concepción y Valdivia, demostrándose cierto ánimo descentralizador que iba de la mano con una serie de proyectos que apuntaban a su participación en la esfera pública.

4 Pierre Bourdieu define el campo cultural como el punto donde convergen todos los espacios de producción cultural (cf. escritores, editores, críticos, empresarios, etc.). Su modelo es de utilidad porque permite explicar la posición social de las obras y sus autores. Al igual que Foucault, reconoce que ninguna obra literaria se encuentra aislada de la estructura social, vale decir, toda obra literaria existe dentro de la cultura, por lo que es indispensable abrir el texto a factores externos. Sin embargo, no se observa a la cultura como un solo bloque homogéneo, sino que se considera la existencia de varios campos de producción cultural, que se influyen y por ende se modifican recíprocamente. Las elecciones estéticas responden siempre a las tensiones y luchas de poder entre los agentes del campo literario, quienes optan por aquellas fórmulas que mejor convienen a sus intereses particulares. 
habría que decir que el leopardo no sólo forma parte del título de la revista, sino también es el significante-significado que abre la primera editorial. Es aquí donde, en lugar de hacerse un manifiesto explícito sobre las posturas político-literarias de la revista, se opta por poner la definición completa sobre el animal:

LEOPARDO. (Del lat. leopardos) m. De los felinos del Viejo Mundo, el leopardo, conocido también con el nombre de pantera, es el que ocupa un área geográfica más extensa. Se lo encuentra, en efecto, en casi toda Asia, desde Manchuria y el S. de Siberia hasta Ceilán, y se extiende por el E. hasta Java y, por el O., hasta el Cáucaso. En África existe desde Marruecos hasta el Cabo de Buena Esperanza. Débese esto a su notable adaptabilidad, pues lo mismo vive en las llanuras y en las montañas que en las grandes selvas, aunque siempre prefiere los lugares en los que hay árboles porque es un excelente trepador y le gusta ponerse en acecho en una rama para caer sobre su presa. Además, es más astuto, más ágil y más atrevido que el león o el tigre, lo que significa ventajas para sobrevivir donde estos grandes parientes suyos van retrocediendo ante la civilización. Se distinguen varias razas geográficas de esta especie; el tamaño oscila, según la raza, entre dos y tres ms. de largo, y el fondo del pelaje, siempre elegantemente sembrado de rosetas negras es en unos casos de color bayo amarillo, y, en otros, casi blanco o de un tono arenoso muy claro. Algunos ejemplares son negros con las manchas de un negro muy profundo y brillante, pero esto no es un carácter racial; cualquier pareja de leopardos puede tener entre sus cachorros uno negro. La bella piel de dicho animal ha sido siempre muy estimada, lo mismo por la dama elegante que por el rey zulú. En el antiguo Egipto era un símbolo de dignidad del sumo sacerdote.

El leopardo caza gacelas, ciervos, jabalíes, y, sobre todo, monos; también mata animales domésticos siempre que puede, y muestra singular preferencia por los perros. Se ha visto a un leopardo entrar en un poblado y llevarse a un perro ante los ojos de su dueño. Algunas veces ataca también a las personas, pero el caso parece menos frecuente que con el león o con el tigre. (Piel de Leopardo no.1, 1)

La extensa definición abre varias posibilidades de lectura. De entrada se plantea su ubicación geográfica en un continente que no es el nuestro. 
El leopardo es autóctono de Asia y África, pero no de América. Se trata de un animal de caza que, gracias a su astucia y agilidad, supera incluso a algunos animales de su misma especie. Pero no es todo, la definición también abarca una dimensión mercantil en el animal importado a territorio nacional, el valor comercial de su codiciada y transable piel.

La elección de este mamífero no pareciera ser casual en el contexto histórico en que surge la revista, donde el leopardo opera a nivel simbólico, en cuanto su piel se vuelve símbolo que se introduce en un escenario en que imperan el "libre mercado, de consumo intensificado de marcas e imágenes" (Cárcamo 53). Se trata de una semántica que remeda aquella que envolvía el discurso económico chileno a principios de los años noventa, según la cual los chilenos eran 'los jaguares de Latinoamérica' debido a sus logros en materia de índices económicos. Así como se había tratado de blanquear y enfriar la imagen-país en la Expo Sevilla ' $92^{5}$, feria en la que Chile participó exportando un iceberg, el discurso económico sobre la realidad nacional estaba armado sobre la base de una imagen exitista, en la cual Chile resultaba ser el país modelo de la región. Por esa época, se decía que Chile era el ejemplo económico a seguir e incluso Jeffrey Sachs, profesor de Harvard y considerado uno de los genios de la economía mundial, señaló:

Chile [...] tiene mucho que enseñar a esta región y al mundo entero. Me parece que Chile puede proporcionar una gran lección, en el sentido que la democracia y la economía van de la mano. [...] Creo [...] que ustedes tendrán éxito, desde la historia y desde los logros de Chile. Todo el mundo los está observando, también mi país, y ustedes pueden constituir un ejemplo maravilloso para el mundo entero. (Citado en Otano 344)

Esta declaración bien refleja el estado anímico de aquellos años. Sachs interpela a un público que puede 'sentirse orgulloso', a un público aleccionador cuyos pasos son un ejemplo a seguir, pues van en camino a traspasar el umbral del desarrollo. Estados Unidos mira a Chile con buenos ojos y ese es motivo más que suficiente para celebrar. No obs-

5 El año 1992 se realiza en Sevilla una feria mundial. En esa instancia, Chile se había dado a conocer al mundo con un iceberg de 68 toneladas, exportado directamente desde los mares antárticos y que obedecía a la estrategia de posicionar a Chile como un país frío y lejano a la visión tropical que el norte suele tener del sur. La frialdad necesaria que, en palabras de Nelly Richard, debe tener "el cálculo y la eficiencia de una realidad tecnificada" (175) opuesta al caos y a la irracionalidad. El gesto premoderno de la escena de José Arcadio Buendía descubriendo el hielo y fundando una estirpe. Ad portas de la democracia, la opción escogida fue mostrar un Chile congelado y contenido, de sus conflictos y su memoria. 
tante, el apelativo 'Chile jaguar' no hace más que formar "parte de una estrategia de exaltación, destinada a suscitar 'orgullo patriótico', la idea de que somos triunfadores" (Moulian 99) y competidores en un contexto internacional ${ }^{6}$. De este modo, la imagen de agresiva competitividad y las cualidades que evidenciaba la definición enciclopédica de la primera editorial de Piel de Leopardo (animal trepador, al acecho, depredador) se aplican en el contexto chileno con una doble función: atraer la inversión extranjera y consolidar el modelo por medio de una identificación de la ciudadanía con él ${ }^{7}$. Es en este período cuando el consumo se masifica y hay un acceso generalizado a "la 'modernidad' de los bienes u objetos que antes estaban restringidos a los ricos" (100) y surge lo que Tomás Moulian denomina el ciudadano credit-card, un modelo de identidad que asocia el progreso (y el crédito) con la díada consumo-ciudadanía.

Con la cita al leopardo como símbolo que caracteriza el debate nacional, la revista está planteando su propia visión sobre el asunto, una visión que, si bien no ataca a la contingencia de modo directo, sí hace una crítica implícita a ésta en la definición que abre su primera editorial. Justamente al resaltar el carácter foráneo del animal, el cual se encuentra principalmente en toda Asia, se alude al modelo importado de libre mercado y a la inclusión de Chile en el quinto lugar de la lista de los países en vías de industrialización, cuyos cuatro primeros lugares son precisamente ocupados por países del sureste asiático: "Singapur, Hong Kong, Taiwán y Malasia” (Otano 358). Piel de Leopardo transforma el significado situado en el contexto económico y lo traslada a un contexto literario para, desde ahí, hacer una lectura a partir del espacio cultural a las producciones que precisamente el modelo deja fuera de este discurso exitista que va de la mano con el discurso de la Nueva Narrativa, nombre también transformado en un slogan, que auguraba a cierto grupo de escritores como la gran promesa literaria de la década.

La polisemia que el nombre adquiere en el contexto político-literario chileno también linda con el significado erótico de la piel fina y precia-

6 En diciembre de 1992 la Cepal emite un informe donde se señala que Chile posee los indicadores económicos más pujantes de Latinoamérica. Ese año, la inflación se había reducido al $12,8 \%$ y el crecimiento había alcanzado un 10,3\%, con un superávit fiscal de 2,5\%. También se habían marcado récords en ahorro; construcción de viviendas; exportaciones; ventas de automóviles; inversiones y ocupación laboral. De hecho, en la encuesta CEP-Adimark de ese mismo mes, un 50,2\% creía que la economía mejoraría el año '93; un 36\% creía que se mantendría y sólo un $8,9 \%$ auguraba un descenso. Mientras que un $68 \%$ opinaba que Chile progresaba, contra un $25 \%$ y un $8 \%$ que sostenían que el país se mantenía estancado o iba en definitiva decadencia. (Otano 345).

7 No me referiré a las discusiones en torno a este lenguaje exagerado sobre Chile y el contraste en términos de recursos, pobreza y cultura. Al respecto remito nuevamente a Tomás Moulián. 
da del leopardo. La idea de una segunda piel usada con fines sexuales o también como un disfraz que invoca salvajismo. La ropa interior de leopardo, los abrigos, las carteras, zapatos, cinturones y cuánto accesorio se pueda encontrar en el comercio, llevan al imaginario de la sensualidad/sexualidad. Son las mujeres, por lo general, quienes visten estas prendas estampadas que imprimen en sus cuerpos la marca del deseo, pero también la marca kitsch de la imitación del animal salvaje. En este último ejemplo, la piel de leopardo opera como pastiche en el sentido definido por Fredric Jameson:

El pastiche, como la parodia, es la imitación de una máscara peculiar, un discurso en una lengua muerta: pero es una práctica neutral de tal imitación, carente de los motivos ulteriores de la parodia, amputada de su impulso satírico, despojada de risas [...]. El pastiche es, pues, una parodia vacía, una estatua con cuencas ciegas. (36-37)

Este pastiche nuevamente nos aproxima a esta semántica del triunfo, al símbolo en su versión vacía de contenido que primaba en el discurso económico de los noventa y que también ha sido absorbido desde el campo de las artes visuales por Bruna Truffa. La artista, en su exposición Si vas para el mall, del año 2002, profundiza las relaciones del arte con el mercado y nos muestra en un cuadro-objeto llamado "Viva la lata", el típico tarro de jurel 'tipo salmón' que se encuentra en los supermercados chilenos, pero esta vez, con el salmón cubierto por las manchas felinas del leopardo. Aquí se encuentra implícita la idea de, como versa el dicho popular, 'pasar gato por liebre', es decir, vender una cosa con el nombre y la etiqueta de otra, porque como bien ocurre con la lata no se trata de salmón real, sino de un jurel que pretende ser su imitación a un precio mucho más reducido. De este modo, lo que Chile estaría vendiendo es una imagen falsa de su desarrollo, una identidad travestida, lo mismo que la Nueva Narrativa lo estaría haciendo de su éxito como lo veremos a continuación.

8 Esta no es la única referencia de Truffa a la 'jaguaridad' de los chilenos. En una exposición anterior, de 1997, la artista gana el primer lugar del concurso Wunter en el Museo Nacional de Bellas Artes con "Made in Chile", óleo en el que en medio del paisaje cordillerano aparece la figura de un hombre o una mujer -no queda claro cuál de ambos- agachado/a en cuatro patas y disfrazado/a de jaguar. El disfraz es evidente, pues las manos están desnudas y en los pies se ven claramente unos calcetines. Lo interesante de la propuesta es que muy sutilmente, en la esquina inferior izquierda del cuadro, aparecen los símbolos característicos de una etiqueta de lavar ropa, justamente el lugar donde se inscribe en las prendas reales el lugar de origen, el "made in", que en el caso de la obra de Truffa remitiría al carácter artificial del animal. 


\section{A la caza de la Nueva Narrativa}

Seis meses antes de la aparición de Piel de Leopardo la revista APSI ${ }^{9}$ había publicado el artículo "Casus belli: todo el poder para nosotros", donde el escritor y en ese entonces editor de Planeta, Jaime Collyer, realizaba una suerte de manifiesto generacional, que, en términos confrontacionales rechazaba a los escritores de las generaciones anteriores:

Se acabaron las contemplaciones: no más tacitas de té en compañía de los viejos maestros, no más talleres literarios a su gusto y medida -ahora los maestros somos nosotros-, no más sonrisas y halagos de los patriarcas del 50 o la generación 'novísima'. Nosotros somos ahora la novedad del año, lo demás es pura y simple redundancia en las páginas sociales. Nuestra obra se sostiene por sí misma, sin necesidad de interesados padrinazgos, porque escribimos como los dioses, con nuestras cicatrices a cuestas y también con humor. (Collyer 40)

Las palabras de Collyer resultaron ser una bomba en el contexto literario. Además de acusar de vejez a sus predecesores y de situarlos como excedentes fotográficos de un panorama de revista, sus palabras iban en picada hacia la llamada generación del ' 50 y los novísimos. La primera fue llamada así por Enrique Lafourcade en 1954 para referirse a los escritores nacidos entre 1920 y $1934^{10}$, mientras que el nombre de la segunda fue acuñado por Juan Agustín Palazuelos ${ }^{11}$, de la mano de José Donoso, en la revista Ercilla de diciembre de $1962^{12}$, como respuesta al recién citado Lafourcade y al desinterés que aquella generación les causaba.

9 La revista APSI aparece en Julio de 1976 y corresponde a una publicación opositora a la dictadura de Augusto Pinochet. Esta revista circula hasta el año 1995, alcanzando un total de 511 números.

10 También llamada Generación del ' 57 por Cedomil Goic. Esta generación se caracteriza principalmente por intentar alejarse del criollismo y por tener el apoyo de la editorial Zig-Zag, en ese entonces, de gran influencia en el mundo editorial chileno.

11 Novelista chileno que acuñó el término 'novísimos' para agrupar a algunos narradores de su generación como Mauricio Wacquez, Poli Délano, Antonio Skármeta y Cristián Huneeus. Palazuelos se desempeñó como crítico literario y periodista cultural en la revista Ercilla, en la cual trabajó entre 1962 y 1963. Publicó dos novelas, Según el orden del tiempo (1962) y Muy temprano para Santiago (1966). Además, colaboró en 1964 con Margarita Aguirre en la creación y el prólogo de una antología poética de Nicanor Parra, La cueca larga y otros poemas.

12 En la misma revista Ercilla, una semana más tarde, José Donoso convoca a una "Jornada para la novísima generación", cuya finalidad es realizar una nueva antología de cuentos que entrase en directa disputa con la realizada por Enrique Lafourcade una década antes (cf. Memoria Chilena) 
La 'Nueva Narrativa', tal como se ha denominado al grupo de escritores identificado por Collyer ${ }^{13}$, ha sido una categorización bastante polémica en las letras nacionales, mientras que, para algunos críticos como Soledad Bianchi, no se trató más que de un fenómeno editorial, para otros, significó la emergencia de "la mejor novela chilena actual" (Franz 109) $)^{14}$.

Mencionar de entrada a este grupo responde a que la posición que ocupó la revista Piel de Leopardo en el campo literario chileno tuvo directa relación con el éxito del fenómeno narrativo de los '90. Esto porque se trasluce cierta rebeldía postromántica en las elecciones estéticas y temáticas que se incluyeron en la revista, sobre todo por su marcada inclinación hacia el género poético, tanto desde el ensayismo crítico como desde la creación literaria y visual, gesto que desafía la excesiva atención que los narradores nacionales tenían en los medios escritos. Así, el número cuatro de la revista (Dic. 1993 - Mar. 1994), en su editorial, da una visión clara de sus objetivos literarios:

Pretendemos, en esta edición, hacer un mentís a aquellos que fagocitan -autores y lectores- del boom novelístico en boga; pequeñas copias o reflejos de ese otro invento comercial que se fraguó en la década del 60 a costa de una delirante adhesión política. En efecto, frente a esta sobreabundancia "balzaciana" queremos resituar el discurso poético mediante una sugerente muestra de textos chilenos. No es que no nos guste la novela; se trata de tomar riesgos y hacer apuestas disensuales. (Piel de Leopardo no.4, 3)

El gesto editorial y selectivo de la revista tuvo como fin desmentir en el plano público el exitismo de la novela chilena de comienzo de década. Dicho mentís pretende contradecir o negar abiertamente la validez de la moda generada por Planeta con su colección Biblioteca del Sur. Corre 1987 y es la primera vez que una empresa extranjera apuesta exclusivamente por autores nacionales en su catálogo ${ }^{15}$. El entusiasmo es grande y se deja sentir en las palabras de Collyer:

13 Jaime Collyer distingue a un número limitado de narradores, entre los que cuentan: Ramón Díaz Eterovic, Pablo Azócar, Carlos Franz, Alberto Fuguet, Gonzalo Contreras, Marco Antonio de la Parra, Rafael Gumucio, Luis Sepúlveda, Hernán Rivera Letelier, Carlos Iturra, Diego Muñoz Valenzuela, Darío Oses, Arturo Fontaine, Pía Barros, Andrea Maturana, Juan Mihovilovich, Ana María del Río y Reinaldo Marchant.

14 Pero el gesto de Jaime Collyer tiene sus antecedentes literarios, pues en el año 1986, Ramón Díaz Eterovic y Diego Muñoz Valenzuela habían publicado Contando el cuento. Antología joven narrativa chilena, y más adelante en 1992, Andar con cuentos. Nueva narrativa chilena.

15 Planeta también expande este proyecto a tierras trasandinas. El objetivo en ambos países es potenciar escrituras de autores nacionales. 
Estamos ya posicionados en todos los frentes, que hemos copado paso a paso, subrepticiamente. Nos hemos infiltrado en los puestos decisivos de las principales editoriales, en la Sociedad de Escritores, la Cámara del Libro y los medios de comunicación, en las productoras audiovisuales y las agencias de publicidad, en las publicaciones especializadas. Nada podrá desalojarnos de las trincheras. Donde caiga o renuncie uno, habrá otros diez para ocupar su lugar. Cualquiera de nosotros que resulte inmolado por la crítica resurgirá de sus propias cenizas, con el apoyo de los demás.

Nos criamos a patadas, algunos de nosotros a culatazos, bajo la indiferencia generalizada, pero somos generosos. [...] Cierto es que algunos, o dos, o tres, guardan en su cajón una medallita innoble, recuerdo de tiempos más lúgubres, pero no importa: vamos a hacer la vista gorda respecto a ese y a otros deslices. (Collyer 40)

Exaltación juvenil u orgullo comercial, lo cierto es que la declaración de Collyer evidencia los espacios de posicionamiento y acción de quienes componen su grupo, pero, además, trasluce ciertas estrategias del discurso castrense para referirse a los movimientos de estos escritores en el campo literario, el cual abiertamente se reconoce aquí como un campo de lucha. Al hablar de los 'frentes' y las 'trincheras', el editor de Planeta avala el proceso de transformación de los agentes literarios en agentes del mercado, pues, con el advenimiento de la democracia, estos términos adquieren la connotación ya no física, sino simbólica, de la herencia económico-militar organizada e institucionalizada. Pero, junto a la visión de los escritores de la Nueva Narrativa en términos de 'ejército', también se estaría apelando a la función burocrática del escritor y a la ocupación de puestos o cargos en las empresas asociadas con el libro y la publicidad, esta última asimilable en igual grado de importancia con las editoriales y los organismos gubernamentales de gestión literaria. Es esto mismo, a su vez, lo que implica el concepto de un escritor 'desechable' que se verá rápidamente reemplazado si flaquea o renuncia en su labor. Al igual que en el supermercado del universo eltitiano de la novela Mano de Obra, el lema implícito en "Casus Bellus: todo el poder para nosotros", pareciera ser: trabajar o morir, no importa cuál, pues siempre habrá alguien disponible para ocupar una vacante.

El deseo y la necesidad de presente, esa urgencia por legitimarse como "la novedad del año" (op. cit.), pareciera llevar a un menosprecio del trabajo con la memoria. Si bien el quiebre institucional de 1973 es 
el hecho reconocido que marca a toda la generación, por otra parte, al incluir la perspectiva del desecho (la abundancia en el número permite el uso de carne de cañón: "donde caiga o renuncie uno habrá otros diez") Collyer estaría avalando el olvido como uno de sus procedimientos. ¿Cuáles son los tiempos lúgubres a los que el escritor hace alusión en APSI? Bien se podría estar refiriendo a los padrinazgos literarios que esta nueva generación rechaza, pero, a su vez, también podría aludir a las filiaciones políticas -con la derecha- de algunos de sus integrantes, a las medallas "innobles" de otro enfrentamiento, al embate político en tiempos de dictadura ${ }^{16}$. Lo cierto es que esto no importa y los reemplazos disponibles se convierten en un número elástico que puede ser pasado por alto en aras de este nuevo pacto comercial de escritura que encierra la idea de un (muy frágil) colectivo, en el cual cada sujeto de escritura se vuelve potencialmente sustituible por uno nuevo. Esto último calza con la crítica a la reproductibilidad y falta de originalidad que se lee en la cuarta editorial de Piel de Leopardo respecto a la Nueva Narrativa, por ser sus escritores "pequeñas copias o reflejos de ese otro invento comercial que se fraguó en la década del 60 a costa de una delirante adhesión política" (3). Nada tendría de singular, para quienes escriben en la revista, este nuevo fenómeno narrativo, pues si antes se trataba de adhesión política ahora se trataría de figuración mediática y adhesión comercial: "Estamos ya posicionados en todos los frentes [...] Nos hemos infiltrado en los puestos decisivos" (Collyer 40). El manifiesto publicado en APSI revela una marcada imaginería bélica-comercial, la cual parece estar internalizada casi de modo inconsciente en el narrador. Esta elección verbal es bastante decidora de la profundidad ideológica forzosamente implantada en la población chilena durante casi veinte años de dictadura militar y su concomitante imposición del paradigma neoliberal, al mismo tiempo que también nos demuestra cómo el campo político-económico ha influido marcadamente en el discurso literario del chile postdictatorial.

Frente a la gustosa aceptación de los narradores de la Nueva Narrativa de su nuevo rol literario-comercial, aquello que podríamos denominar una postura cercana a la del grupo heterónomo en el arte ${ }^{17}$,

16 Hay todo un mito literario con respecto a este tema. Roberto Bolaño alude ficcionalmente a él en su novela Nocturno de Chile, donde el sacerdote Sebastián Urrutia Lacroix rememora sus actividades, como crítico, en la casa de Maria Canales, escritora que organizaba veladas literarias en el mismo lugar donde se torturaban desaparecidos.

17 Para analizar estas posiciones tanto en el campo de poder como en su propia estructura interna, Bourdieu define el comportamiento de dos grupos fundamentales, perfectamente distinguidos por su antagonismo. Se trata del grupo heterónomo y el grupo autónomo. Por supuesto, no son los dos únicos productores de arte, son simplemente los dos más radicales, 
la revista Piel de Leopardo recurre a distintas estrategias de enunciación. Además de negar la cadena comercial donde el lector es un mero consumidor y de despreciar la cantidad literaria en aras de la calidad, la revista busca abrir espacios y crear redes entre distintas manifestaciones que no tienen cabida ni resonancias en el lugar de la cultura oficialista, léase, por ejemplo, los espacios de los grandes consorcios editoriales como Planeta y Alfaguara, o, por el lado de los medios, en la "Revista de Libros" de El Mercurio. Por otro lado, opta por la revalorización de la crítica literaria como una escritura que teje una serie de relaciones culturales desde el análisis de los textos. La crítica se transforma en un actante esencial para merodear los espacios del poder, porque en su función política sería capaz de interferir y resistir en los modos y las relaciones que se imponen para comprender la cultura y las lecturas que la mayoría de las veces consensúan con las que el mercado asigna para comprender la literatura y las políticas textuales. Como señala Jesús Sepúlveda:

\section{Piel de Leopardo rompió entonces ese descampado crítico manufacturado por los consorcios editoriales y la prensa co- mercial, reseñando justamente aquellos libros que no tenían recepción crítica ni eran parte del tinglado editorial, aunque su calidad fuese similar o mejor a lo recogido por la crítica oficialista. Hay que pensar que en ese momento los portales de internet aún no estaban masificados, por tanto muchas}

por lo que son fácilmente definibles. El grupo autónomo se distingue por su independencia con respecto al estado económico. No son productores masivos de arte, su prestigio descansa en que no conceden nada al público. Son los defensores del "arte puro", del arte por el arte. Naturalmente, sus políticas de inclusión son sumamente estrictas. Únicamente un selecto grupo de artistas, aquellos que ya se han consagrado, que forman ya parte del canon o no tardan en ingresar a él, son admitidos dentro del campo. El grupo autónomo, al destinar su producción a una elite restringida, no mueve grandes cantidades de dinero. No es el capital económico el que nutre a los integrantes de este grupo. Su aliciente es lo que Bourdieu denomina el 'capital simbólico', es decir, el reconocimiento entre intelectuales. No se trata de un reconocimiento masivo. Todo lo contrario, el productor de arte puro busca que otros productores de arte puro lo reconozcan y admiren, se trata finalmente de un reconocimiento entre similares.

El arte heterónomo, en cambio, se distingue por la flexibilidad de sus políticas de inclusión. Estos productores de arte son los que se dirigen al público masivo, pues finalmente lo que buscan es el capital económico. Precisamente por eso el campo permite entre sus integrantes a todo tipo de autores, pues su bandera no es la defensa de un arte puro, al que por cierto cuestionan severamente acusándolo de arrogante, pretencioso y poco accesible. Justifican su postura precisamente en el hecho de que cuentan con mayor aceptación popular, lo que se convierte en una legitimación en tanto que el público decide y ellos cuentan, con el beneficio económico de esa decisión.

El campo autónomo y el heterónomo, conviene insistir, no son los únicos. Se trata de dos campos completamente antagónicos, por lo que sus políticas son fáciles de definir. Pero entre uno y otro extremo, se ubican otros tantos productores de arte con sus propias políticas de inclusión y exclusión. 
obras de notable calidad permanecían invisibles. (Jesús Sepúlveda en entrevista)

\section{El poeta-leopardo}

Inclinarse por la crítica y sobre todo por la poesía o por escritores ajenos a la Nueva Narrativa es un gesto contrahegemónico a las políticas editoriales en auge en Chile durante este período. No es casual entonces que en el segundo número de Piel de Leopardo aparezca un artículo de Danilo Santos dedicado a una de las novelas de Mauricio Wacquez, representante de los novísimos; y, en el tercero, una entrevista del poeta Jesús Sepúlveda a Claudio Giaconni, perteneciente a la generación encabezada por Lafourcade. Justamente las dos generaciones citadas en el manifiesto de Collyer. No se trata de un volver a las formas de narrar anteriores, sino de reconocer herencias literarias y de resituar el discurso en una lectura actual y local. Esto se hace aún más visible en el primer número de la revista, donde aparece una crítica del escritor Jaime Valdivieso titulada: "La subversión lógica de la Nueva Novela de Juan Luis Martínez".

Publicada en $1975^{18}$, pero reeditada por segunda vez diez años más tarde (precisamente dos años antes del proyecto Biblioteca del Sur), la Nueva Novela entra en pugna con el concepto de novela característico de los autores de la Nueva Narrativa ${ }^{19}$. Mientras que, para estos últimos -y a pesar de su escritura multifacética en cuanto a temas y estilos-, narrar tiene que ver con contar, con la idea de construcción de un relato, trama y argumento, en fin, con el rechazo a la experimentación formal (cf. Cánovas), para Juan Luis Martínez, al contrario, la definición de novela se deslinda de estos marcos. La Nueva Novela es un libro objeto, el cual a pesar de llamarse así

no tiene nada de novela, sino de pura poesía, pero dentro de un circuito distinto: allí donde la ambigüedad, el sentido suspendido, se logra quebrando la racionalidad, donde el mundo referencial se neutraliza a sí mismo por medio de múltiples significantes que ponen distintos significados sin que jamás lleguemos al último. (Piel de Leopardo no.1, 6)

Precisamente, la obra de Martínez no aprehende la narratividad que implica el término novela como categoría de taxonomización genérica, sino que apuesta por las relaciones azarosas y no causales del signifi-

18 También se ha dicho que fue publicada por primera vez en 1977.

19 Las cursivas son de la autora. 
cado. También conviven en ella diversos tipos de significantes como dibujos, textos e imágenes que abren espacios diferentes al concepto de novela tradicional. No obstante, es la poesía lo que más bulle entre sus páginas. De hecho, La Nueva Novela incluye una revista de poesía hecha por Martínez $z^{20}$, la cual sólo quedó como proyecto, pues nunca llegó a publicarse en ese formato (cf. Hidalgo). La posición literaria y el concepto que emana de ella en el artículo publicado por Piel de Leopardo, pueden entenderse precisamente como esta mixtura genérica que confronta las 'N' de Nueva Narrativa con las iniciales del texto de Martínez. La misma revista de Jesús Sepúlveda, Alexis Figueroa, Guillermo Valenzuela, Jaime Lizama, Álvaro Leiva y Manuel Eduardo Pertier, es un texto abierto que incluye desde reseñas críticas sobre teoría literaria y del arte, hasta artículos sobre cine y música, pasando por fotografías, cuentos, entrevistas y, sobre todo, análisis y creación poética.

Si hay que hablar de poesía y escena chilena en Piel de Leopardo, se tiene que partir citando el articulo "Ciudad poética en la transición chilena", de Luis Ernesto Cárcamo-Huechante, aparecido en el número especial sobre revistas de la Revista de Crítica Cultural. Aquí, la relación de la poesía con el entorno neo-modernizador de la urbe santiaguina se invoca a través de la figura del leopardo, que opera como símbolo del extrañamiento del poeta en la ciudad, equivalente a "aquella figuración del poeta-cisne realizada por Charles Baudelaire, en medio de la moderna y modernizadora experiencia citadina del París de mitad del siglo diecinueve" (Cárcamo-Huechante 52). Mientras que el cisne del poema "Le cygne" opera como metáfora de la "nueva realidad del poeta en cuanto especie en peligro de extinción dentro de la urbe moderna [...], [e]l leopardo de la revista chilena se inserta en un registro análogo, en la medida en que se vuelve una entidad extraña al paisaje urbano de fines del siglo veinte" (op. cit.). La analogía cisne/leopardo hecha por este académico no es antojadiza, pues precisamente la relación entre la ciudad y el poeta es una de las temáticas tratadas en los cinco números de la revista. Baudelaire aparece citado directamente desde el primer número con el artículo de Miguel Vicuña "Doble ciudad. Notas sobre un poema de Baudelaire" (Piel de Leopardo no. 1, 16-17), y también, indirectamente, a través de la semántica escogida para ciertos artículos. Por ejemplo, cuando Jesús Sepúlveda entrevista a Claudio Giaconni se refiere a él en términos de un "paseante" (Piel de Leopardo no. 3, 20),

20 La revista supuestamente se llamaba Entregas de plancha, al parecer denominada así como un homenaje al pintor dadaísta Man Ray y su obra Cadeau, en la que se ponía en duda la utilidad de los objetos al poner clavos en el lugar donde la plancha servía para alisar la ropa. 
mientras que el mismo Cárcamo, quien también participó en la revista como colaborador, crea el sustantivo "errancia" para hablar de la escritura de Álvaro Mutis (Piel de Leopardo no. 2, 6). En ambos casos, las palabras entre comillas nos acercan subrepticiamente a la figura del flâneur, citado, como bien lo detecta Cárcamo, en una crítica de Guillermo Valenzuela al poemario Pena de Extrañamiento de Enrique Linh, en el que se recorre "el cuerpo particular de tres ciudades: New York, Barcelona y Santiago de Chile. [...] [E]n relación a la figura del flâneur baudeleriano [que], [...] se expande, se multiplica y se anula en el registro de la ciudad" (Piel de Leopardo no. 1, 7).

Al elegir la figura del leopardo, lo que en realidad se hace es simbolizar a este poeta extraño. El tardío gesto romántico de los autores se evidenciaría en la relación de estos con el canon poético nacional. En los cinco números, se incluyen creaciones de poetas emergentes o poco conocidos como Mario Romero, Víctor Hugo Díaz, Isabel Larraín, Ángel Escobar y Egor Mardones, entre otros, a la vez que textos críticos sobre poetas cuyas relaciones vitalistas con la poesía remiten a la correspondencia entre arte y vida. En varios artículos se menciona los registros de Charles Baudelaire, Arthur Rimbaud, Rodrigo Lira, Enrique Lihn, Charles Bukowski y el recién comentado Juan Luis Martínez, con lo cual se descubre la huella espectral de los "poetes (sic) maudits" (Cárcamo 53), un tipo de escritor y una condición que no eran validados por la visión de la Nueva Narrativa. En Piel de Leopardo, al contrario, lo que se busca es usar la tradición pero reactualizándola, tal como ocurre en el número tres de la revista cuando se cita un texto de Gabriel Mistral. Aquí, en lugar de elegir uno de sus famosos poemas los editores optan por "Caperucita Roja"21, texto que no tiene el final feliz característico del cuento de hadas, sino uno horripilante, en el que la pequeña niña es devorada por el depredador.

Apropiarse también de la herencia de las vanguardias es otra estrategia con que Piel de Leopardo nos habla de una opción estética que busca la autonomía. Para detectar esto basta con detenernos en su primera portada, donde la imagen escogida corresponde a una mujer desnuda, tendida en medio de un prado boscoso y con una lámpara de gas en la mano izquierda. La imagen, que es una cita literal a Étant Donnés ${ }^{22}$, la

21 Perteneciente a la sección "Cuentos" de su poemario Ternura.

22 Étant Donnés: 1. La chute d' eau, 2. Le gaz d' eclairage (Dados: 1. La caída de agua, 2. El gas del alumbrado) es un diorama que fue instalado en el Museo de Arte de Filadelfia en 1968, dos años después de la muerte del artista, y que se mantiene allí hasta nuestros días. Se trata de una vieja puerta de madera estilo español que posee dos pequeños agujeros a través de los cuales el espectador puede ver parte del cuerpo desnudo de una mujer tendida sobre la maleza. Este 
última obra de Marcel Duchamp, realizada entre 1946 y 1966, inquieta. El cuerpo desnudo se encuentra iluminado sobre un pastizal denso, oscuro, que contrasta con el claro cielo que sirve de fondo. La elección de este diorama ${ }^{23}$ en el número inaugural no es antojadizo y marca la línea editorial de la revista, pues el trabajo de este artista resultó ser la vía para una estética nueva y subversiva que negaba toda vinculación con grupo artístico o tendencia alguna y que, además, criticaba el arte como institución y fulminaba la idea de una obra y de un artista sacralizados. Desde este punto de vista, es el espectador quien hace la obra y es precisamente esto lo que ocurre con Étant Donnés, montaje al que sólo se puede acceder a través de los agujeros de una pesada puerta de madera. Lo real de esta escena es precisamente su irrealidad, la extrañeza que causa en el espectador, "la farsa de construir una escena [...] cuya verdad está en el engaño... y en el rendimiento (visual) de la apariencia" (Arqueros 11). A través de esta primera portada, Piel de Leopardo ocupa un lugar específico en el campo artístico-literario, apoderándose de la herencia vanguardista europea para resituar el discurso nacional. La misma revista sería como esa puerta, en la que finalmente es el lectorespectador quien construye el texto.

Por último, esta autonomía recién mencionada estaría asociada a las estrategias publicitarias y de distribución de la revista. Piel de Leopardo sobrevivió gracias a la gestión de su propio equipo, pues vale destacar que los escasos avisajes no fueron suficientes. Entre los avisadores esporádicos se encontraban el Bar La Unión y la Editorial Cuarto Propio, además de una botillería ${ }^{24}$, una tienda de ropa usada, la librería del Fondo de Cultura Económica, el Bar-Restaurant La Tecla, el café La Pérgola de La Plaza, la Librería Mímesis, Artesanías Nehuén, la Feria del Disco, el libro-café La Tasca Mediterránea, la librería Latinoamericana, la Universidad Arcis y la Librería Mil Novecientos. Se trata siempre de los mismos avisadores pero que aparecen dispersos en los cinco números. Sumado a estas entradas, Piel de Leopardo se editó gracias al aporte de sus miembros, al de algunos amigos y a las suscripciones que mantenían en distintas ciudades. Sin embargo, será en el tercer y quinto número cuando el respaldo institucional se

cuerpo, de piernas abiertas y al cual no se le puede ver el rostro, llama la atención no sólo por su erotismo sino también porque su sexo se haya desplazado hacia su costado izquierdo.

23 Según la definición otorgada por la RAE, un diorama es una panorámica de lienzos transparentes y pintados por ambas caras, lo que genera un efecto visual en que, gracias a la luz, se logra ver en un mismo lugar dos objetos distintos.

24 En el segundo número se encuentra la publicidad de una botillería en Bellavista. Lamentablemente sólo se puede leer "Botillería El" (39), pues falta el resto de la página. Nuestra edición fue examinada de los archivos de la Biblioteca Nacional de Chile. 
amplíe. El número tres de la revista contó con el aporte del Fondo a Iniciativas Culturales de la Secretaría de Comunicación y Cultura ${ }^{25}$ y del Instituto de la Juventud, mientras que el quinto, correspondiente al período '94-'95, el más extenso en cantidad de páginas ${ }^{26}$, se financia con el aporte del Fondo de Desarrollo de la Cultura y las Artes del Ministerio de Educación. Lamentablemente luego de este volumen la revista no vuelve a aparecer, pues los proyectos de sus editores no hicieron posible la redacción de un nuevo número. No obstante, Piel de Leopardo revive en formato electrónico entre los años 2000 y 2008, con Jorge Lagos Nilsson a la cabeza, pero ahora con otros interereses, orientados al debate latinoamericano y a la difusión de un pensamiento crítico localizado que busca poner en diálogo la pregunta sobre nuestras culturas y su inserción en el mundo global.

\section{Conclusiones}

Durante los primeros años de la transición a la democracia, el pensamiento literario que había alcanzado hegemonía era aquel que se amoldaba mejor a las coordenadas ideológicas de la época y que resultaba ser una herencia de la dictadura militar y de sus políticas neoliberales. Para algunos grupos, como resulta ser la Nueva Narrativa encabezada por el escritor Jaime Collyer, la literatura pareciera ser un producto que se vende a las editoriales para que éstas a su vez la vendan a los consumidores en una cadena en que lo más importante pareciera ser posicionarse en los puestos que las instituciones literarias ofrecen. La efervescencia de esa época, tanto en lo económico como en lo cultural de la realidad chilena, está permeada por un discurso militar y monetario casi inocente frente al cual la revista Piel de Leopardo responde críticamente con un objetivo claro, exponer "la mirada más bien desplazada y desjerarquizada de un sujeto que hace crítica en un espacio cultural peligrosamente vacío, sin interconexiones o redes posibilitadoras de diálogos" (Jaime Lizama 27).

Centrados en la figura del poeta-leopardo como sujeto crítico que recorre la ciudad, el modo de intervenir de la revista

era político en su sentido de ruptura y disensión, asumiendo una perspectiva callejera que centraba la ciudad como espacio de enunciación. [...] En tal sentido, desplazamos las temáticas

25 Entidad, aquel año, bajo el mando de la Secretaría General de Gobierno.

26 Este número tiene 51 páginas. 
de interés oficial y académico (la memoria, la democracia, la utopía, los DD.HH., etc.) a un área de mayor vitalidad e interés inmediato; la calle, la música y la fotografía, por ejemplo. (Jesús Sepúlveda en entrevista)

Vale destacar que el interés por crear un sujeto crítico que tensione los espacios de la cultura se hace presente en todos los números de la revista, pero sobretodo en el cuarto, donde se incluye un dossier sobre la crítica literaria a cargo de Jaime Lizama. Con la inclusión de este documento la revista nuevamente toma posiciones en el campo literario a partir de una polémica iniciada por la revista Simpson Siete, de la Sociedad de Escritores de Chile, y continuada en el suplemento "Literatura y Libros" del diario La Época, en octubre de 1993, en relación a la necesidad e importancia de la crítica literaria en el medio nacional, sus fallas y sus aciertos. Mencionamos esta polémica porque la mirada que Piel de Leopardo tiene sobre la crisis de la cultura crítica en nuestro país se corresponde con la postura que ella asumía frente a la Nueva Narrativa. A la hegemonía denunciada con respecto al fenómeno Planeta, es posible agregar en futuros análisis sobre esta revista una interpretación de la crisis de la cultura desde el prisma de la crítica y la falta de espacios para ejercer otros paradigmas literarios y culturales ajenos a la jerarquía oficial, posturas que entienden la cultura desde un arquetipo monológico y mercantil, y que niegan la posibilidad de unir fronteras textuales. Posiciones literarias contra las cuales Piel de Leopardo despliega todas sus estrategias de escritura y de creación, apostando por un arte heterogéneo y relativamente autónomo que incluya a aquellos escritores que el campo desplaza hacia los extremos, extremos que para la revista tienen tanto o más valor que el centro.

\section{Bibliografía}

\section{Bibliografía revistas}

Piel de Leopardo, (1992), n 1, agosto, Santiago, Chile. . (1993), nº 2, enero, Santiago, Chile. (1993), no 3, junio, Santiago, Chile. . (1993), no 4, diciembre, Santiago, Chile. . (1994), nº 5, octubre, Santiago, Chile. 


\section{Bibliografía crítica}

Arquero, Gonzalo. "Como basura en el ojo. (Nota sobre la portada de Piel de Leopardo $\mathrm{N}^{\circ} 1$ )". Piel de Leopardo, $\mathrm{n}^{\circ} 2$, ene.-mar, Santiago, pp. 10-11. (1993).

Bianchi, Soledad. "De qué hablamos cuando decimos Nueva Narrativa chilena". Nueva Narrativa chilena. Ed. Carlos Olivárez. Santiago de Chile: LOM, 1997, pp. 29-34.

Bolaño, Roberto. Nocturno de Chile. Barcelona: Anagrama, 2005.

Bourdieu, Pierre. Las reglas del arte. Génesis y estructura del campo literario. Barcelona: Anagrama, 1995.

Cárcamo-Huechante, Luis E.). "Ciudad poética en la transición chilena". Revista de Crítica Cultural, no 31, 2055, junio, Santiago, pp. 51-57.

"Alvaro Mutis y su épica de la errancia". Piel de Leopardo, 1993, nº 2, Ene-mar, Santiago, pp. 6-7.

Cánovas, Rodrigo. Novela chilena, nuevas generaciones: el abordaje de los huérfanos. Santiago de Chile: Ediciones Universidad Católica de Chile, 1997.

Collyer, Jaime. "Casus Belli o todo el poder para nosotros". Apsi, no 415, 1992, febrero-marzo, Santiago, pp. 40.

Díaz Eterovic R. Muñoz Valenzuela D. Andar con cuentos. Nueva narrativa chilena (Antología). Santiago de Chile: Editorial Mosquito, 1992.

. Contando el cuento. Antología joven narrativa chilena. Santiago de Chile: Editorial Sin Fronteras, 1986

Eltit, Diamela. Mano de Obra. Santiago de Chile: Seix Barral, 2002.

Franz, Carlos. "Nueva Narrativa, viejas picas". Nueva Narrativa chilena. Ed. Carlos Olivárez. Santiago de Chile: LOM, 1997, pp. 107-113.

Goic, Cedomil. Historia de la novela hispanoamericana. Valparaíso: Universitarias, 1972.

Hidalgo, Daniel. (2009). "Esbozo de biografía". Borradores de Juan Luis Martinez. Web. 20 ago. <http://borradoresdejlm. blogspot.com/search/label/biografia>. 
Jameson, Fredric. "El posmodernismo y el pasado". Ensayos sobre el posmodernismo. Trad. Esther Pérez. Buenos Aires: Taurus, 1994.

Lizama, Jaime. "Dossier crítica". Piel de Leopardo. № 4. Diciembre de 1993 - Marzo de 1994, Santiago, pp. 27-32.

Moulian, Tomás. Chile actual o anatomía de un mito. Santiago de Chile: LOM, 2002.

Otano, Rafael. Nueva crónica de la transición. Santiago de Chile: LOM, 2006.

Real Academia Española. Diccionario de la lengua española (21a. ed.). Madrid: Espasa-Calpe, 1992.

Richard, Nelly. Residuos y metáforas (Ensayos de crítica cultural sobre el Chile de la Transición). Santiago de Chile: Cuarto Propio, 2001.

Sepúlveda, Jesús. "Entrevista: Claudio Giaconni o el desasosiego del paseante". Piel de Leopardo, n 3, agosto, Santiago, 1993, pp. 20-22.

Piel de Leopardo: 14 años después. Entr. Macarena Silva. México, 2009, Sept.

Valdivieso, Jaime. "La subversión lógica de la Nueva Novela de Juan Luis Martínez". Piel de Leopardo, nº 1, 1992, agosto, Santiago, pp. 6.

Vicuña, Miguel. "Doble ciudad. Notas sobre un poema de Baudelaire". Piel de Leopardo, no 1, 1992, agosto, Santiago, pp. 16-17. 